\title{
Ultra-processed foods, incident overweight and obesity, and longitudinal changes in weight and waist circumference: the Brazilian Longitudinal Study of Adult Health (ELSA-Brasil)
}

\author{
Scheine Leite Canhada ${ }^{1,2}$ (1), Vivian Cristine Luft ${ }^{1,3,4, *}$, Luana Giatti ${ }^{5}$, Bruce \\ Bartholow Duncan ${ }^{1,2}$, Dora Chor ${ }^{6}$, Maria de Jesus M da Fonseca ${ }^{6}$, Sheila Maria \\ Alvim Matos ${ }^{7}$, Maria del Carmen Bisi Molina ${ }^{8}$ (i), Sandhi Maria Barreto ${ }^{5}{ }^{(0)}$, Renata \\ Bertazzi Levy9 and Maria Inês Schmidt ${ }^{1,2}$ \\ 'Postgraduate Program in Epidemiology, Universidade Federal do Rio Grande do Sul, Faculdade de Medicina - \\ Campus Saúde, R. Ramiro Barcelos 2400, Porto Alegre, RS 90035-003, Brazil: ${ }^{2}$ National Health Technology \\ Assessment Institute, CNPq, Porto Alegre, RS, Brazil: ${ }^{3}$ Postgraduate Program in Food, Nutrition and Health, \\ Universidade Federal do Rio Grande do Sul, Porto Alegre, RS, Brazil: ${ }^{4}$ Food and Nutrition Research Centre (CESAN) - \\ Hospital de Clínicas de Porto Alegre, Universidade Federal do Rio Grande do Sul, Porto Alegre, RS, Brazil: \\ ${ }_{5}^{5}$ Postgraduate Program in Public Health and School of Medicine \& Clinical Hospital, Universidade Federal de Minas \\ Gerais, Belo Horizonte, MG, Brazil: 'National School of Public Health, Fundação Oswaldo Cruz, Rio de Janeiro, RJ, \\ Brazil: ${ }^{7}$ Postgraduate Program in Collective Health, Instituto de Saúde Coletiva, Universidade Federal da Bahia, \\ Salvador, BA, Brazil: ${ }^{8}$ Postgraduate Program in Nutrition and Health, Universidade Federal do Espírito Santo, Vitória, \\ ES, Brazil: ' Department of Preventive Medicine, School of Medicine, Universidade de São Paulo, São Paulo, SP, Brazil
}

Submitted 20 December 2018: Final revision received 13 May 2019: Accepted 24 June 2019: First published online 17 October 2019

\begin{abstract}
Objective: To evaluate the association of ultra-processed food (UPF) consumption with gains in weight and waist circumference, and incident overweight/obesity, in the Brazilian Longitudinal Study of Adult Health (ELSA-Brasil) cohort.

Design: We applied FFQ at baseline and categorized energy intake by degree of processing using the NOVA classification. Height, weight and waist circumference were measured at baseline and after a mean 3-8-year follow-up. We assessed associations, through Poisson regression with robust variance, of UPF consumption with large weight gain (1.68 kg/year) and large waist gain $(2.42 \mathrm{~cm} /$ year), both being defined as $\geq 90$ th percentile in the cohort, and with incident overweight/obesity. Setting: Brazil.

Participants: Civil servants of Brazilian public academic institutions in six cities ( $n$ 11 827), aged 35-74 years at baseline (2008-2010).

Results: UPF provided a mean 24.6 (SD 9.6) \% of ingested energy. After adjustment for smoking, physical activity, adiposity and other factors, fourth (>30.8\%) $v$. first $(<17.8 \%)$ quartile of UPF consumption was associated (relative risk $(95 \% \mathrm{CI})$ ) with 27 and $33 \%$ greater risk of large weight and waist gains $(1.27(1.07,1.50)$ and 1.33 $(1.12,1.58))$, respectively. Similarly, those in the fourth consumption quartile presented $20 \%$ greater risk $(1.20(1.03,1.40))$ of incident overweight/obesity and $2 \%$ greater risk $(1.02 ;(0.85,1.21))$ of incident obesity. Approximately $15 \%$ of cases of large weight and waist gains and of incident overweight/obesity could be attributed to consumption of $>17 \cdot 8 \%$ of energy as UPF.

Conclusions: Greater UPF consumption predicts large gains in overall and central adiposity and may contribute to the inexorable rise in obesity seen worldwide.
\end{abstract}

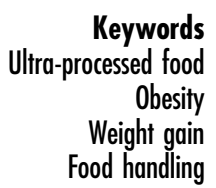

The world has witnessed a progressive, major increase in the burden of obesity over recent decades. Since 1980, the prevalence has doubled in more than seventy out of
195 countries $^{(1)}$ and obesity has become a major problem not only in high-income but also in low- and middleincome countries ${ }^{(2)}$. The Global Burden of Disease study 
estimates that, in 2015 , obesity affected 603.7 million (95\% CI 588.2-619.8 million) adults and $107 \cdot 7$ million (95\% CI 98.7-118.4 million) children worldwide, leading to major morbidity and mortality ${ }^{(1)}$.

A better understanding of what has changed over recent decades that could possibly be associated with population weight gain (for example, forms of eating) is of paramount importance. Increased consumption of ultra-processed foods and beverages is a likely candidate ${ }^{(3)}$ as an increase in ultra-processed food intake has paralleled the obesity pandemic, replacing traditional local eating patterns throughout the world ${ }^{(4-9)}$

A recent cross-sectional evaluation of nineteen European countries showed that a 1 percentage point greater consumption of ultra-processed foods was associated with a 0.25 percentage point greater obesity prevalence ${ }^{(10)}$. However, more direct evidence from longitudinal studies to document the role of ultra-processed foods in adiposity gain over time and in the incidence of overweight/obesity is scant. We found only one such study, based on university graduates in Spain ${ }^{(11)}$.

Our purpose was to investigate the prospective association of ultra-processed food and beverage consumption with gains in weight and waist circumference, as well as with incident overweight/obesity among those not having excess weight at baseline and with incident obesity among those overweight at baseline.

\section{Methods}

\section{Study design and population}

The Brazilian Longitudinal Study of Adult Health (ELSA-Brasil) is a multicentre cohort aiming primarily to address risk factors for and progression of diabetes, CVD and other related chronic diseases. As previously described $^{(12,13)}$, between August 2008 and December 2010, we recruited 15105 active and retired, non-pregnant employees aged 35-75 years from public institutions of higher education and research located in six Brazilian capital cities (Salvador, Belo Horizonte, Rio de Janeiro, São Paulo, Vitória and Porto Alegre) and applied a series of questionnaires as well as laboratory and clinical examinations $^{(14,15)}$. Between 2012 and 2014, participants returned to the research centres for further examination, during which the follow-up weight was obtained. All participants provided written informed consent, and research protocols were approved by the ethics committee of all the institutions involved.

Among the 15105 participants enrolled, we excluded participants without baseline weight or waist data ( $n$ 5), without data on food frequency ( $n$ 36), with an implausible total food intake ( $n$ 212), with missing data on other covariates at visit 1 ( $n$ 423) or with self-reported chronic diseases or medication use that could influence food consumption ( $n$ 1653). We also excluded 131 participants who died before visit 2 and an additional 716 did not attend visit 2 . Finally, we excluded participants with bariatric surgery between visits ( $n 51)$ or with no weight or waist data at follow-up ( $n$ 51). The final sample consisted of 11827 participants. For specific analyses related to incident overweight/ obesity (BMI $\geq 25 \mathrm{~kg} / \mathrm{m}^{2}$ ) and incident obesity (BMI $\geq 30$ $\mathrm{kg} / \mathrm{m}^{2}$ ), we made further specific exclusions related to baseline BMI, as shown in Fig. 1.

\section{Baseline measurements}

We interviewed participants at baseline with standardized questionnaires to ascertain sociodemographic characteristics (age, sex, centre, race/skin colour, educational level, family income), previous medical history, smoking (current and previous) and physical activity, the latter defined using the International Physical Activity Questionnaire (IPAQ) section on leisure activity. The participant's race/colour was self-reported. Per capita family income, also based on self-report, was calculated as the total family monthly income divided by the number of family members and expressed as a multiple of the Brazilian minimum wage.

We also obtained several anthropometric measures following internationally standardized protocols ${ }^{(16,17)}$. Waist circumference and weight were measured when fasting and with an empty bladder at the research clinics. During measurement, participants were dressed in standardized clothing without spectacles and other personal objects. We measured height to the nearest $0.1 \mathrm{~cm}$ (Seca model SE-216, Hamburg, Germany). We obtained waist circumferences with a $150 \mathrm{~cm}$ inelastic measuring tape (Mabis-Gulick, Waukegan, IL, USA) at the midpoint between the inferior edge of the costal border and the iliac crest in the mid-axillar line. We measured body weight with an electronic scale with maximum capacity of $300 \mathrm{~kg}$ (Toledo, São Bernardo do Campo, Brazil). Quality control measures were uniform across all centres. BMI was calculated as measured weight (in kilograms) divided by the square of measured height (in metres).

\section{Dietary assessment}

Food consumption was evaluated at baseline through a previously validated FFQ with 114 food items ${ }^{(18)}$. For each item, we obtained the frequency of consumption in the last 12 months (with eight response options: 'more than 3 times/day', '2-3 times/day', 'once daily', '5-6 times/ week', '2-4 times/week', 'once/week', '1-3 times/month' and 'never/almost never') and the number of portions consumed (using standardized portion sizes). The amount (grams per day) of each food item was calculated by multiplying the number of portions by the portion weight and the consumption frequency weight $(3$ for $>3$ times/d, 2 for 2-3 times/d, 1 for 1 time/d, 0.8 for 5-6 times/week, 0.4 for 2-4times/week, 0.1 for 1 time/week, 0.07 for 1-3 times/month and 0 for never/almost never). 


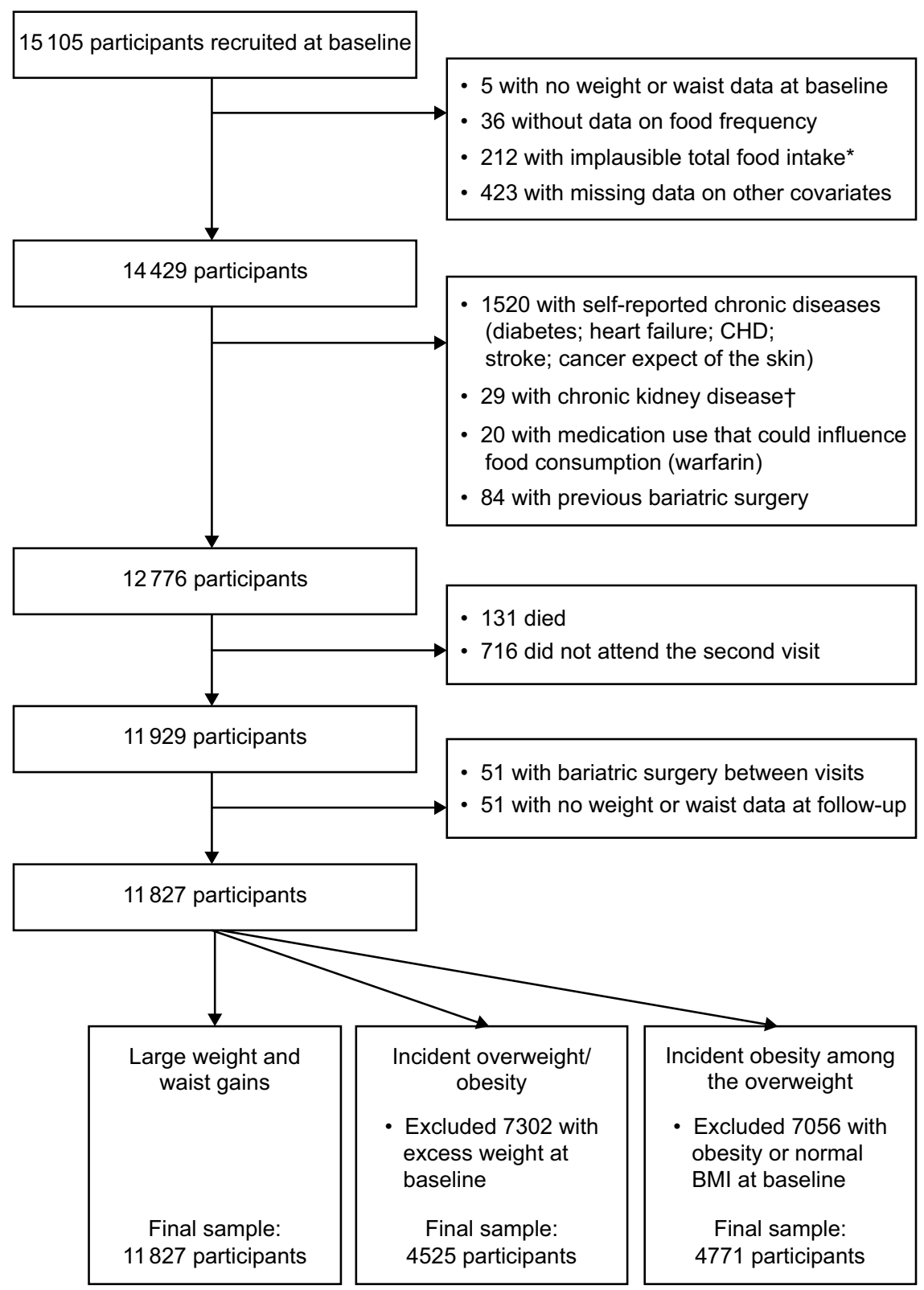

Fig. 1 Flowchart of participants in the present study. ${ }^{*}$ Implausible total food intake defined as $<2510$ or $>25104 \mathrm{~kJ}(<600$ or $>6000 \mathrm{kcal})$. †Chronic kidney disease defined as glomerular filtration rate of $\leq 45 \mathrm{ml} / \mathrm{min}$ per $1.73 \mathrm{~m}^{2}$

We employed the University of Minnesota Nutrition Data System for Research (NDSR) software to estimate the nutritional composition and energy value of recorded foods. For each of the food items, we imputed the respective 99th percentile consumption for participants with consumption above this percentile. Finally, we calculated the energy content of each food item by multiplying the daily food intake in grams by the energy in $100 \mathrm{~g}$ as estimated by the software (= intake grams $\times$ energy content per $100 \mathrm{~g} / 100$ ).

We applied the NOVA classification to allocate foods consumed into three groups according to the extent and purpose of their industrial processing: (i) non- or minimally processed foods and culinary ingredients; (ii) processed foods; and (iii) ultra-processed foods ${ }^{(19)}$. The energy consumption in each food group was then calculated by summing energy from the included food items, allowing the calculation of the relative contribution of each group to the total daily energy value.

\section{Outcomes}

We calculated annual weight gain for each participant as the weight difference, in kilograms, between the baseline and follow-up visit, divided by the time, in years, between the two visits. We defined a large annual weight gain as equal to or greater than the 90 th percentile $(\geq 1.68 \mathrm{~kg} /$ year $)$ gain in the sample. We defined a large annual gain in waist 
circumference similarly, considering its 90th percentile $(\geq 2.42 \mathrm{~cm} /$ year). We investigated incident overweight and obesity $\left(\mathrm{BMI} \geq 25 \mathrm{~kg} / \mathrm{m}^{2}\right)$ at follow-up among those not having excess weight $\left(\mathrm{BMI}<25 \mathrm{~kg} / \mathrm{m}^{2}\right)$ at baseline and incident obesity (BMI $\left.\geq 30 \mathrm{~kg} / \mathrm{m}^{2}\right)$ at follow-up among those overweight $\left(25 \mathrm{~kg} / \mathrm{m}^{2}<\mathrm{BMI} \leq 30 \mathrm{~kg} / \mathrm{m}^{2}\right)$ at baseline.

\section{Statistical analysis}

We describe participant characteristics and outcomes using absolute and relative frequencies for categorical variables, and as mean and standard deviation or median and 25th-75th percentiles for continuous variables.

We characterized ultra-processed food consumption (percentage of total daily energy intake from these foods) as a continuous variable and expressed results for a $15 \%$ increase in total energy consumed (approximately the interquartile range). We also categorized such consumption into quartiles based on the overall analytic sample and used the first quartile as a reference.

We analysed associations of ultra-processed food intake with a large annual weight or waist circumference gain and with incident overweight/obesity using Poisson regression with robust variance, progressively adjusting for age, sex, colour/race, centre, school achievement, and then smoking and physical activity. Finally, for weight/waist gain and for incident overweight/obesity, we additionally adjusted for baseline BMI, and for waist gain, we additionally adjusted for baseline waist circumference. In this full model, we tested interactions by categories of sex (men and women), race/colour (whites and non-whites) and age ( $<60$ years $v$. $\geq 60$ years).

We assessed the linearity of the associations between ultra-processed food consumption and these outcomes using restricted cubic splines ${ }^{(20)}$. We performed additional analyses: (i) to further adjust for total energy intake; (ii) to further adjust for fruit and vegetable consumption; and (iii) to investigate gains associated with non-beverage ultra-processed foods in which we adjusted also for ultraprocessed beverage intake. We calculated the adjusted population-attributable fraction directly from the Poisson regressions ${ }^{(21,22)}$. All analyses were conducted with the statistical software package SAS version 9.4, except for the adjusted population-attributable fractions which were calculated using the statistical software package Stata version 11.1.

\section{Results}

Of the 11827 individuals analysed, 6507 (55.0\%) were women, $6169(52.2 \%)$ self-declared as being white and 6388 (54.0\%) had completed college/university. At baseline, mean age was 51.3 (SD 8.7) years, mean BMI was $26.8(\mathrm{SD} 4.6) \mathrm{kg} / \mathrm{m}^{2}$ and mean waist circumference was $90.6(\mathrm{SD} 12 \cdot 5) \mathrm{cm}$. Mean total energy consumption was 10979 (SD 3908) kJ/d (2624 (SD 934) kcal/d); 12267 (SD 4063$) \mathrm{kJ} / \mathrm{d}(2932$ (SD 971) kcal/d) for men and 9924 $(\mathrm{sD} 3431) \mathrm{kJ} / \mathrm{d}(2372(\mathrm{sD} 820) \mathrm{kcal} / \mathrm{d})$ for women. Foods and beverages classified as ultra-processed foods accounted for a mean of 24.6 (SD 9.6) \% of total daily energy consumption; in natura, minimally processed or culinary ingredients for $64.1 \%$; and processed foods for $11.3 \%$. Table 1 lists the main foods and beverages classified as ultra-processed foods. Bread, sweets/candies, sweetened sodas/juices and salty pastries/chips accounted for more than $50 \%$ of the total energy consumption from ultra-processed foods; other frequent items ( $>5 \%$ ) included cakes, processed meat, pasta/pizzas, cookies/crackers and mayonnaise/margarine/cream cheese.

Table 1 Frequency of consumption of specific ultra-processed foods and beverages and their contribution to energy intake. Brazilian Longitudinal Study of Adult Health (ELSA-Brasil), 2008-2010 ( $n 11827$ )

\begin{tabular}{|c|c|c|c|c|}
\hline \multirow[b]{3}{*}{ Food item } & \multicolumn{4}{|c|}{ Ultra-processed food consumption } \\
\hline & \multicolumn{2}{|c|}{$\begin{array}{l}\text { Consumption } \\
\text { frequency } \\
\text { (\% of total ultra- } \\
\text { processed foods) }\end{array}$} & \multicolumn{2}{|c|}{$\begin{array}{l}\text { Contribution to } \\
\text { energy intake } \\
\text { (\% of total daily } \\
\text { energy intake) }\end{array}$} \\
\hline & Mean & SD & Mean & SD \\
\hline Bread & $23 \cdot 1$ & $17 \cdot 3$ & $5 \cdot 6$ & 4.8 \\
\hline Sweets, candies & $13 \cdot 2$ & $11 \cdot 0$ & $3 \cdot 4$ & 3.4 \\
\hline Sweetened sodas/juices & 9.4 & 11.5 & $2 \cdot 4$ & $3 \cdot 2$ \\
\hline Salty pastries, chips & 8.7 & 8.7 & $2 \cdot 1$ & $2 \cdot 2$ \\
\hline Cakes & 8.5 & 9.5 & $2 \cdot 2$ & $2 \cdot 7$ \\
\hline Processed meat & $8 \cdot 2$ & $8 \cdot 4$ & 1.9 & 1.9 \\
\hline Pasta and pizzas & $7 \cdot 6$ & $7 \cdot 4$ & 1.9 & 1.9 \\
\hline Cookies, crackers & 7.5 & $10 \cdot 1$ & 1.8 & 2.5 \\
\hline Mayonnaise, margarine, cream cheese & $6 \cdot 7$ & $7 \cdot 4$ & 1.6 & $1 \cdot 7$ \\
\hline Yoghurt (with additives) & $3 \cdot 9$ & $6 \cdot 2$ & 0.9 & 1.4 \\
\hline Cereal bars & $2 \cdot 0$ & $5 \cdot 0$ & 0.5 & $1 \cdot 3$ \\
\hline Distilled alcoholic beverages & 1.0 & $4 \cdot 3$ & 0.2 & 0.8 \\
\hline Soup & 0.2 & 0.8 & 0.1 & 0.2 \\
\hline
\end{tabular}


Table 2 Characteristics of the study sample according to quartile of ultra-processed food consumption. Brazilian Longitudinal Study of Adult Health (ELSA-Brasil), 2008-2010 (n 11 827)

\begin{tabular}{|c|c|c|c|c|c|c|c|c|c|c|}
\hline \multirow[b]{3}{*}{ Characteristic } & \multicolumn{8}{|c|}{ Ultra-processed food consumption ( $\%$ of total daily energy intake) } & \multirow{2}{*}{\multicolumn{2}{|c|}{$\begin{array}{c}\text { Total } \\
(n 11827)\end{array}$}} \\
\hline & \multicolumn{2}{|c|}{$\begin{array}{l}\text { Quartile 1 } \\
(0-17.79 \%) \\
(n 2956)\end{array}$} & \multicolumn{2}{|c|}{$\begin{array}{c}\text { Quartile } 2 \\
(17.79-23.91 \%) \\
(n 2957)\end{array}$} & \multicolumn{2}{|c|}{$\begin{array}{c}\text { Quartile } 3 \\
(23.91-30.84 \%) \\
(n 2957)\end{array}$} & \multicolumn{2}{|c|}{$\begin{array}{c}\text { Quartile } 4 \\
(30 \cdot 84-73.84 \%) \\
(n 2957)\end{array}$} & & \\
\hline & $\begin{array}{l}\text { Mean, } n \\
\text { or } \\
\text { median }\end{array}$ & $\begin{array}{l}\text { SD, \% or } \\
\text { P25-P75 }\end{array}$ & $\begin{array}{l}\text { Mean, } n \\
\text { or } \\
\text { median }\end{array}$ & $\begin{array}{l}\text { SD, \% or } \\
\text { P25-P75 }\end{array}$ & $\begin{array}{l}\text { Mean, } n \\
\text { or } \\
\text { median }\end{array}$ & $\begin{array}{l}\text { SD, \% or } \\
\text { P25-P75 }\end{array}$ & $\begin{array}{l}\text { Mean, } n \\
\text { or } \\
\text { median }\end{array}$ & $\begin{array}{l}\text { SD, \% or } \\
\text { P25-P75 }\end{array}$ & $\begin{array}{l}\text { Mean, } n \\
\text { or } \\
\text { median }\end{array}$ & $\begin{array}{l}\text { SD, \% or } \\
\text { P25-P75 }\end{array}$ \\
\hline $\begin{array}{l}\text { Age (years), mean and SD } \\
\text { Sex, } n \text { and } \%\end{array}$ & $53 \cdot 6$ & 8.5 & $51 \cdot 7$ & $8 \cdot 6$ & $50 \cdot 7$ & 8.5 & $49 \cdot 3$ & $8 \cdot 7$ & $51 \cdot 3$ & $8 \cdot 7$ \\
\hline $\begin{array}{l}\text { Female } \\
\text { Skin colour/race, } n \text { and \% }\end{array}$ & 1350 & $46 \cdot 7$ & 1576 & $53 \cdot 1$ & 1716 & $57 \cdot 4$ & 1865 & $62 \cdot 7$ & 6507 & $55 \cdot 0$ \\
\hline Black & 628 & $21 \cdot 7$ & 504 & $17 \cdot 0$ & 440 & $14 \cdot 7$ & 341 & 11.5 & 1913 & $16 \cdot 2$ \\
\hline Brown & 972 & 33.6 & 902 & 30.4 & 789 & $26 \cdot 4$ & 658 & $22 \cdot 1$ & 3321 & $28 \cdot 1$ \\
\hline White & 1174 & $40 \cdot 6$ & 1453 & 48.9 & 1652 & $55 \cdot 2$ & 1890 & 63.5 & 6169 & $52 \cdot 2$ \\
\hline Asian & 75 & 2.6 & 86 & 2.9 & 76 & 2.5 & 66 & 2.2 & 303 & 2.6 \\
\hline Indigenous & 43 & 1.5 & 24 & 0.8 & 33 & $1 \cdot 1$ & 21 & 0.7 & 121 & 1.0 \\
\hline $\begin{array}{l}\text { Per capita family income } \\
\text { (minimum wages/month), } \\
\text { median and P25-P75 }\end{array}$ & 5 & $3-8$ & 5 & $3-9$ & 6 & $4-10$ & 6 & $4-9$ & 5 & $3-9$ \\
\hline School achievement, $n$ and & & & & & & & & & & \\
\hline Less than elementary & 264 & $9 \cdot 1$ & 131 & 4.4 & 113 & $3 \cdot 8$ & 80 & $2 \cdot 7$ & 588 & $5 \cdot 0$ \\
\hline Elementary & 250 & 8.6 & 211 & $7 \cdot 1$ & 142 & 4.7 & 136 & 4.6 & 739 & $6 \cdot 2$ \\
\hline Secondary & 1126 & 38.9 & 1056 & $35 \cdot 6$ & 1009 & 33.7 & 921 & 30.9 & 4112 & 34.8 \\
\hline College/university & 1252 & $43 \cdot 3$ & 1571 & 52.9 & 1726 & $57 \cdot 7$ & 1839 & $61 \cdot 8$ & 6388 & $54 \cdot 0$ \\
\hline Smoking, $n$ and $\%$ & & & & & & & & & & \\
\hline Never & 1586 & $54 \cdot 8$ & 1696 & $57 \cdot 1$ & 1779 & 59.5 & 1866 & $62 \cdot 7$ & 6927 & 58.6 \\
\hline Ex-smoker & 902 & $31 \cdot 2$ & 886 & 29.8 & 857 & 28.7 & 764 & $25 \cdot 7$ & 3409 & $28 \cdot 8$ \\
\hline Current & 404 & 14.0 & 387 & $13 \cdot 0$ & 354 & $11 \cdot 8$ & 346 & 11.6 & 1491 & $12 \cdot 6$ \\
\hline $\begin{array}{l}\text { Physical activity at leisure } \\
\text { time (MET } \times \text { min/week), } \\
\text { median and P25-P75 }\end{array}$ & 240 & $0-960$ & 264 & $0-960$ & 244 & $0-954$ & 240 & $0-929$ & 240 & $0-960$ \\
\hline BMI $\left(\mathrm{kg} / \mathrm{m}^{2}\right)$, mean and SD & $26 \cdot 8$ & $4 \cdot 6$ & $26 \cdot 8$ & 4.6 & $26 \cdot 8$ & 4.5 & $26 \cdot 8$ & $4 \cdot 8$ & $26 \cdot 8$ & 4.6 \\
\hline $\begin{array}{l}\text { Waist circumference }(\mathrm{cm}) \text {, } \\
\text { mean and SD }\end{array}$ & 91.6 & $12 \cdot 4$ & $90 \cdot 7$ & $12 \cdot 2$ & $90 \cdot 2$ & $12 \cdot 5$ & 89.7 & $12 \cdot 7$ & 90.6 & 12.5 \\
\hline $\begin{array}{l}\text { Total daily energy intake } \\
(\mathrm{kJ} / \mathrm{d}) \text {, mean and SD }\end{array}$ & 10803 & 3837 & 10979 & 3895 & 11025 & 3933 & 11104 & 3958 & 10979 & 3908 \\
\hline $\begin{array}{l}\text { Total daily energy intake } \\
(\mathrm{kcal} / \mathrm{d}), \text { mean and SD }\end{array}$ & 2582 & 917 & 2624 & 931 & 2635 & 940 & 2654 & 946 & 2624 & 934 \\
\hline $\begin{array}{l}\text { Fruits and vegetable intake } \\
\text { (\% of total daily energy), } \\
\text { mean and SD }\end{array}$ & $11 \cdot 0$ & $6 \cdot 3$ & $9 \cdot 8$ & 5.4 & 9.0 & $5 \cdot 2$ & $7 \cdot 6$ & 4.4 & 9.4 & 5.5 \\
\hline $\begin{array}{l}\text { Sweetened beverages } \\
\text { (\% of total daily energy), } \\
\text { mean and SD }\end{array}$ & 1.0 & $1 \cdot 6$ & 1.9 & 2.4 & $2 \cdot 8$ & $3 \cdot 2$ & 3.9 & $4 \cdot 2$ & $2 \cdot 4$ & 3.2 \\
\hline
\end{tabular}

P25, 25th percentile; P75, 75th percentile; MET, metabolic equivalent of task.

Table 2 describes the sample characteristics according to quartile of daily consumption of ultra-processed foods when expressed as a percentage of daily energy intake. Compared with those in lower quartiles of ultra-processed food consumption, those in the fourth quartile were more frequently younger, women, white, with higher income, more educated, never smokers, with higher energy intake, less consumption of fruits and vegetables and greater ingestion of sweetened beverages. Sample characteristics were similar when we considered only those eligible for the outcomes of incident overweight/obesity and obesity.

After a mean of 3.8 (SD 0.4) years of follow-up, mean weight gain was 0.3 (SD 1.2) $\mathrm{kg} /$ year and mean waist circumference gain was $0.7(\mathrm{SD} 1.5) \mathrm{cm} /$ year. Among those not overweight at baseline, 972 (21.5\%) became overweight or obese; among those overweight, 748 (15.7\%) became obese.

As seen in Table 3, incidence of large weight and waist gains increased monotonically with increasing consumption of ultra-processed foods, although incident overweight and obesity did not show such uniformly graded increases over the quartiles.

Restricted cubic spline regression, after adjusting for possible confounders, revealed statistically significant, positive relationships of greater ultra-processed food consumption with large weight and waist gains and with the incidence of overweight/obesity among those not overweight/obese at baseline, as seen by the $95 \%$ confidence bands. The magnitude of these associations increased monotonically as ultra-processed food consumption 
Table 3 Frequency of large ( $\geq 90$ th percentile) gains in weight and waist circumference and the incidence of overweight and obesity, according to quartile of ultra-processed food consumption. Brazilian Longitudinal Study of Adult Health (ELSA-Brasil), 2008-2010 ( $n$ 11 827)

\begin{tabular}{|c|c|c|c|c|c|c|c|c|}
\hline \multirow{2}{*}{$\begin{array}{l}\text { Ultra-processed food consumption } \\
\text { (\% of total daily energy intake) }\end{array}$} & \multicolumn{2}{|c|}{$\begin{array}{l}\text { Large weight gain } \\
\qquad(n 11827)\end{array}$} & \multicolumn{2}{|c|}{$\begin{array}{c}\text { Large waist } \\
\text { circumference } \\
\text { gain } \\
(n 11827)\end{array}$} & \multicolumn{2}{|c|}{$\begin{array}{l}\text { Incidence of } \\
\text { overweight and } \\
\text { obesity }^{\star} \\
(n 4527)\end{array}$} & \multicolumn{2}{|c|}{$\begin{array}{l}\text { Incidence of } \\
\text { obesity } \\
(n 4771)\end{array}$} \\
\hline & Cases & $\%$ & Cases & $\%$ & Cases & $\%$ & Cases & $\%$ \\
\hline Quartile 1 (0-17.79\%) & 211 & $7 \cdot 1$ & 205 & 6.9 & 199 & $17 \cdot 6$ & 164 & $13 \cdot 9$ \\
\hline Quartile 2 (17.79-23.91\%) & 286 & 9.7 & 265 & $9 \cdot 0$ & 233 & 21.0 & 200 & $16 \cdot 2$ \\
\hline Quartile 3 (23.91-30.84\%) & 318 & $10 \cdot 7$ & 319 & $10 \cdot 8$ & 272 & $24 \cdot 2$ & 181 & $15 \cdot 2$ \\
\hline Quartile 4 (30.84-73.84 \%) & 378 & $12 \cdot 8$ & 394 & $13 \cdot 3$ & 268 & $23 \cdot 1$ & 203 & $17 \cdot 4$ \\
\hline Total & 1193 & $10 \cdot 1$ & 1183 & $10 \cdot 0$ & 972 & 21.5 & 748 & $15 \cdot 7$ \\
\hline
\end{tabular}

${ }^{*}$ Among those with $\mathrm{BMl}<25 \mathrm{~kg} / \mathrm{m}^{2}$ at baseline.

†Among those with BMI between 25 and $30 \mathrm{~kg} / \mathrm{m}^{2}$ at baseline.

expanded from low levels to approximately $25 \%$ of total daily energy intake. Then, the associations with large weight and waist gains slowly plateaued ( $P$ for test of non-linearity $=0.23$ and $0 \cdot 17$, respectively), while that with incident overweight/obesity completely flattened $(P=0.03$ for non-linearity). In contrast, among those overweight at baseline, gradual increases in incident obesity were seen only with higher levels of ultra-processed food intake (approximately $20 \%$ of total daily energy; $P=0.56$ for non-linearity), although this increase in risk never achieved statistical significance (Fig. 2).

Table 4 shows the associations of ultra-processed foods with each outcome in progressively adjusted models. First, ultra-processed food intake was analysed continuously, with associations being expressed for a $15 \%$ increase in total energy consumed as ultra-processed foods. Given the non-linear association for incident overweight/obesity with increased levels of ultra-processed food intake in restricted cubic spline analyses, we have not expressed this association with the intake analysed continuously. In crude analyses, the increment for each of the remaining outcomes was associated with moderately increased risk: large weight and waist gains (relative risk $(\mathrm{RR})=1 \cdot 36,95 \% \mathrm{CI}$ $1 \cdot 26,1 \cdot 47$; and $\mathrm{RR}=1 \cdot 42,95 \% \mathrm{CI} 1 \cdot 31,1 \cdot 53$, respectively) and obesity $(R R=1 \cdot 20,95 \% \mathrm{CI} 1.09,1.33)$. After adjustments, associations decreased but remained statistically significant for large weight and waist circumference gains: an increment of $15 \%$ in consumption was associated with an increased risk of 12 and $15 \%(\mathrm{RR}=1 \cdot 12,95 \% \mathrm{CI} 1 \cdot 03$, $1 \cdot 22$; and $\mathrm{RR}=1 \cdot 15$, $95 \% \mathrm{CI} 1.06,1 \cdot 25)$, respectively. Consistent with the restricted cubic spline regression analyses (Fig. 2), associations for incident obesity among those overweight at baseline were not statistically significant ( $\mathrm{RR}=1 \cdot 06,95 \% \mathrm{CI} 0.96,1 \cdot 17$ ).

As also shown in Table 4, comparing the fourth with the first quartile of ultra-processed food consumption, we again found moderate increased risk for the four outcomes. In crude analyses associations were all statistically significant, with increased risk of 79, 92, 31 and 25\% for a large weight gain, a large waist gain, incident overweight/obesity and incident obesity $(\mathrm{RR}=1.79,95 \% \mathrm{CI} 1.52,2 \cdot 10$;
$\mathrm{RR}=1.92,95 \%$ CI $1 \cdot 64,2 \cdot 26 ; \mathrm{RR}=1 \cdot 31,95 \%$ CI $1 \cdot 11$, 1.54; and $\mathrm{RR}=1.25,95 \% \mathrm{CI} 1.04,1.51)$, respectively. After multiple adjustments, associations decreased somewhat and remained statistically significant for all outcomes except incident obesity among those overweight at baseline, with increased risk of $27,33,20$ and $2 \%$ for these same outcomes $(\mathrm{RR}=1 \cdot 27,95 \% \mathrm{CI} 1 \cdot 07,1 \cdot 50 ; \mathrm{RR}=1 \cdot 33,95 \% \mathrm{CI}$ $1 \cdot 12,1 \cdot 58 ; \mathrm{RR}=1 \cdot 20,95 \% \mathrm{CI} 1 \cdot 03,1 \cdot 40 ;$ and $\mathrm{RR}=1 \cdot 02,95 \%$ CI $0 \cdot 85,1.21)$, respectively. The only interaction that was statistically significant was that for race/colour groups $(P=0.02)$ when evaluating a large weight gain, with non-whites showing a stronger association.

In additional models (not shown in Table 4), associations remained essentially unchanged after further adjustment for total energy intake, having increased risk of 27 , 36, 22 and $2 \%$ for a large weight gain, a large waist gain, incident overweight/obesity and incident obesity $(\mathrm{RR}=1 \cdot 27,95 \% \mathrm{CI} 1 \cdot 07,1 \cdot 51 ; \mathrm{RR}=1 \cdot 36,95 \% \mathrm{CI} 1 \cdot 14$, $1 \cdot 61 ; \mathrm{RR}=1 \cdot 22,95 \% \mathrm{CI} 1 \cdot 04,1.42 ;$ and $\mathrm{RR}=1 \cdot 02,95 \%$ CI $0.85,1.21)$, respectively. Only minimal changes were seen also after further adjustment for fruit and vegetable consumption, the increased risks being 33, 38, 22 and $1 \%$ for these same outcomes ( $\mathrm{RR}=1 \cdot 33,95 \% \mathrm{CI}$ $1 \cdot 11,1 \cdot 58 ; \mathrm{RR}=1 \cdot 38,95 \% \mathrm{CI} 1 \cdot 16,1 \cdot 64 ; \mathrm{RR}=1 \cdot 22,95 \%$ CI $1.04,1.42$; and $R R=1.01,95 \%$ CI $0.85,1.21$ ), respectively.

We also investigated these associations after excluding sweetened beverages from the ultra-processed foods classification. In this analysis, we added sweetened beverage consumption to model 4 adjustments. Associations were similar, with increased risk of 34,42 , 24 and $3 \%$ for a large weight gain, a large waist gain, incident overweight/obesity and incident obesity $(\mathrm{RR}=1 \cdot 34$, $95 \%$ CI 1.13, 1.58; RR = 1.42, $95 \%$ CI 1.20, 1.69; RR = 1.24, $95 \%$ CI 1.06, 1.44; and $\mathrm{RR}=1.03,95 \%$ CI $0.87,1 \cdot 22$ ), respectively.

Population-attributable fraction analyses showed that $14 \cdot 1,15 \cdot 2$ and $14.9 \%$ of large weight gains, large waist gains and incident cases of overweight/obesity, respectively, could be attributable to high (greater than the first quartile) consumption of ultra-processed foods and beverages. 


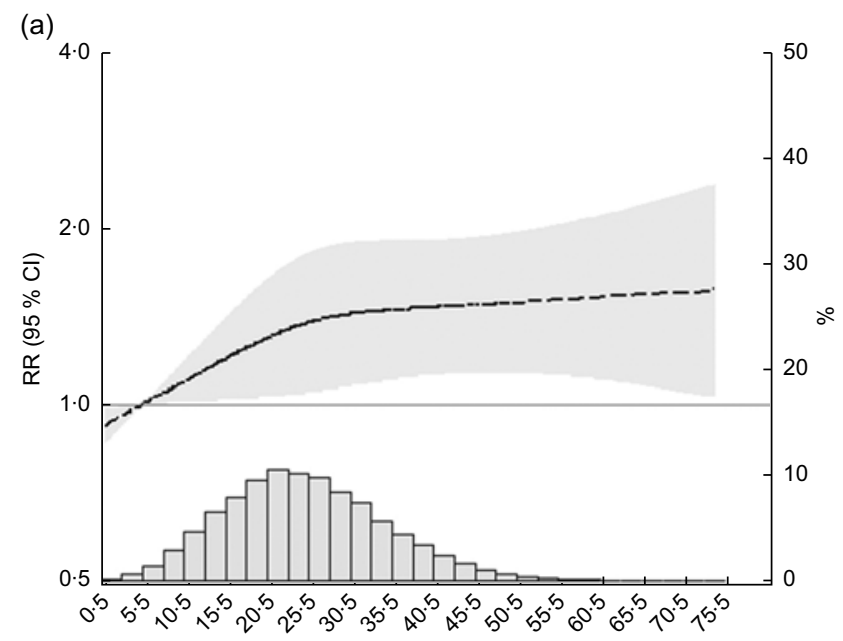

Ultra-processed food intake (\% of total daily energy intake)

(c)

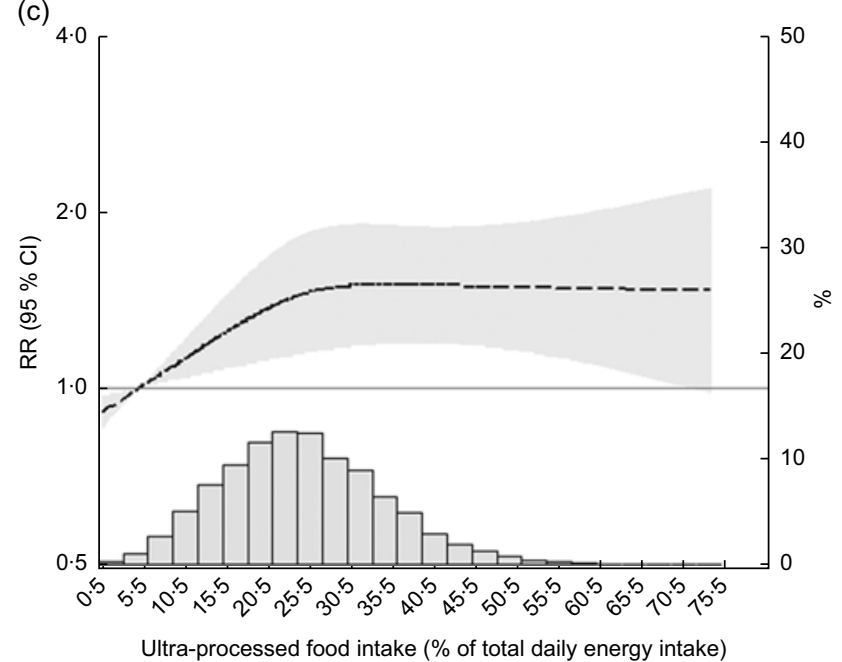

(b)

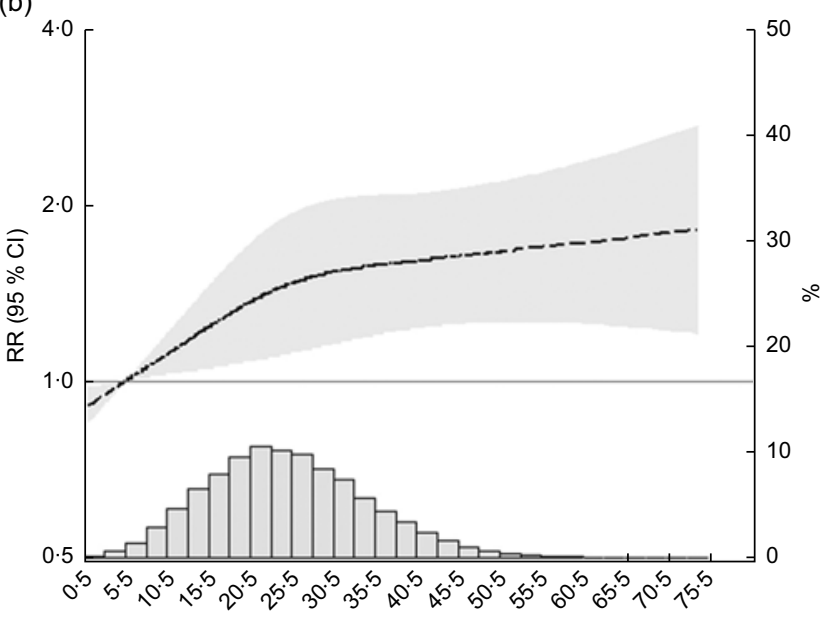

Ultra-processed food intake (\% of total daily energy intake)

(d)

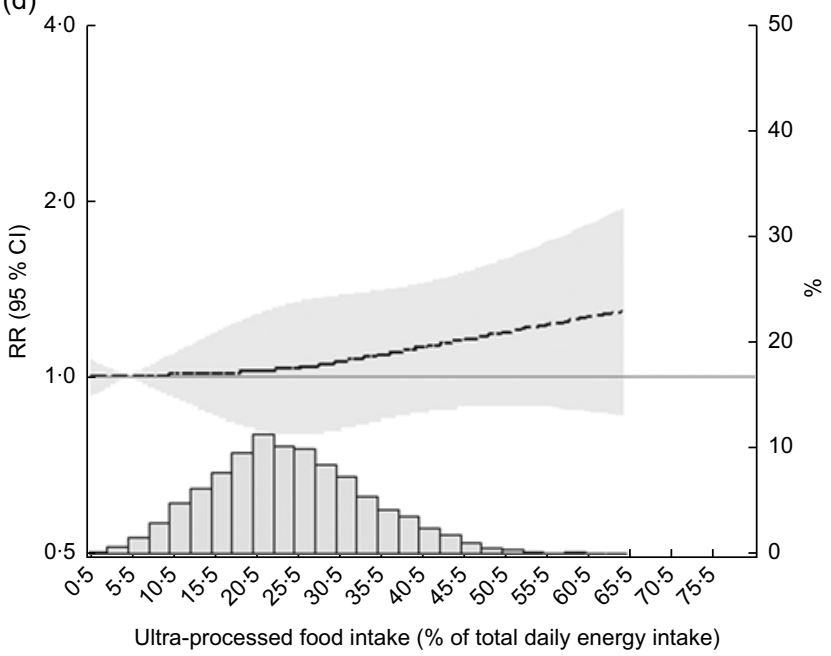

Fig. 2 Associations (--, relative risk $(\mathrm{RR}) ; \square, 95 \% \mathrm{Cl}$ ) of increasing intake of ultra-processed foods with (a) a major weight gain ( $\geq 90$ th percentile; $\geq 1.7 \mathrm{~kg} /$ year), (b) a major waist gain ( $\geq 90$ th percentile; $\geq 2.4 \mathrm{~cm} /$ year), (c) incident overweight or obesity among those without excess weight at baseline and (d) incident obesity among those overweight at baseline, after a mean 3.8-year follow-up. Brazilian Longitudinal Study of Adult Health (ELSA-Brasil), 2008-2010 ( $n 11827$ ). Associations were obtained through restricted cubic spline analyses adjusted for age, sex, colour/race, school achievement, per capita family income, smoking, physical activity and baseline waist (for waist gain) or BMI (for weight gain, incident overweight and obesity and incident obesity among those overweight). The $y$-axis to the right of each plot indicates the relative frequency (\%) of the ultra-processed food intake displayed in the superimposed distribution curve

\section{Discussion}

We found an approximately $20-30 \%$ greater risk of large weight and waist circumference gains and greater incidence of overweight/obesity over 3.8 years of follow-up, comparing those in the highest with those in the lowest quartile of ultra-processed food consumption. Although these associations are of small to moderate size, given the high frequency of ultra-processed food consumption, adjusted populationattributable fractions for all outcomes were approximately $15 \%$, demonstrating the large potential public health significance of this exposure.

The role of processed foods in health and disease has been investigated in recent decades, more specifically with respect to sweetened beverages and processed meats, generally showing positive associations with weight gain and obesity ${ }^{(23-25)}$. Our use of the NOVA classification of processed foods allowed us to include other foods suffering similar processing mechanisms and thus to assess ultraprocessing of foods more broadly. Application of this classification in Europe revealed linearly greater obesity rates according to the frequency of ultra-processed food consumption across countries ${ }^{(10)}$. Positive cross-sectional associations have been also observed in studies conducted in Brazil and other Latin American countries ${ }^{(26-28)}$.

To our knowledge, the only other prospective study reporting the association of ultra-processed foods with incident overweight/obesity is that of Mendonça et al. ${ }^{(11)}$. 
Table 4 Association of ultra-processed food consumption (\% of total daily energy intake) with large weight and waist circumference gains ${ }^{*}$, with incident overweight and obesity among those without excess weight at baseline and with incident obesity among those overweight at baseline, after a mean 3.8-year follow-up. Brazilian Longitudinal Study of Adult Health (ELSA-Brasil), 2008-2010 ( $n$ 11 827)

\begin{tabular}{|c|c|c|c|c|c|c|c|c|c|}
\hline & \multirow{2}{*}{$\begin{array}{l}\text { Ultra-processed food } \\
\text { consumption }\end{array}$} & \multicolumn{2}{|c|}{ Model 1} & \multicolumn{2}{|c|}{ Model 2} & \multicolumn{2}{|c|}{ Model 3} & \multicolumn{2}{|c|}{ Model 4} \\
\hline & & RR & $95 \% \mathrm{Cl}$ & $\mathrm{RR}$ & $95 \% \mathrm{Cl}$ & $\mathrm{RR}$ & $95 \% \mathrm{Cl}$ & RR & $95 \% \mathrm{Cl}$ \\
\hline \multirow{4}{*}{$\begin{array}{l}\text { Large weight gain }(\geq 90 \text { th } \\
\text { percentile: } \geq 1.68 \mathrm{~kg} / \text { year }) \\
(n 11827)\end{array}$} & $\begin{array}{l}\text { For each } 15 \% \\
\text { point increase }\end{array}$ & $1 \cdot 36$ & $1.26,1.47$ & $1 \cdot 13$ & $1 \cdot 04,1 \cdot 23$ & $1 \cdot 14$ & $1 \cdot 05,1 \cdot 24$ & $1 \cdot 12$ & $1.03,1.22$ \\
\hline & Quartile 2 & 1.35 & $1.14,1.61$ & $1 \cdot 17$ & $0.98,1.38$ & $1 \cdot 17$ & $0.99,1.39$ & $1 \cdot 15$ & $0.97,1.37$ \\
\hline & Quartile 3 & 1.51 & $1 \cdot 28,1 \cdot 78$ & 1.20 & $1.01,1.42$ & 1.22 & $1.03,1.44$ & $1 \cdot 20$ & $1.02,1.42$ \\
\hline & Quartile 4 & 1.79 & $1 \cdot 52,2 \cdot 10$ & 1.28 & $1.08,1.52$ & $1 \cdot 30$ & $1 \cdot 10,1.54$ & $1 \cdot 27$ & $1.07,1.50$ \\
\hline \multirow{4}{*}{$\begin{array}{l}\text { Large waist circumference } \\
\text { gain }(\geq 90 \text { th percentile: } \\
\geq 2 \cdot 42 \mathrm{~cm} / \text { year }) \\
(n 11827)\end{array}$} & $\begin{array}{l}\text { For each } 15 \% \\
\text { point increase }\end{array}$ & 1.42 & $1.31,1.53$ & $1 \cdot 14$ & $1 \cdot 05,1 \cdot 24$ & $1 \cdot 15$ & $1.06,1.25$ & $1 \cdot 15$ & $1.06,1.25$ \\
\hline & Quartile 2 & 1.29 & $1.08,1.54$ & $1 \cdot 11$ & $0.93,1.32$ & $1 \cdot 11$ & $0.93,1.33$ & $1 \cdot 11$ & $0.94,1.33$ \\
\hline & Quartile 3 & 1.56 & $1 \cdot 32,1 \cdot 84$ & $1 \cdot 21$ & $1.02,1.43$ & 1.23 & $1.04,1.46$ & $1 \cdot 23$ & $1.04,1.46$ \\
\hline & Quartile 4 & 1.92 & $1 \cdot 64,2 \cdot 26$ & $1 \cdot 30$ & $1 \cdot 10,1.55$ & 1.33 & $1.12,1.57$ & 1.33 & $1.12,1.58$ \\
\hline \multirow{4}{*}{$\begin{array}{l}\text { Incident overweight/obesity } \\
\left(\mathrm{BMI} \geq 25 \mathrm{~kg} / \mathrm{m}^{2}\right)^{\star} \\
(n 4527)\end{array}$} & For each $15 \%$ & \multicolumn{8}{|c|}{ (non-linear association in restricted cubic spline regression) } \\
\hline & Quartile 2 & $1 \cdot 19$ & $1.00,1.41$ & $1 \cdot 18$ & $0.99,1.40$ & $1 \cdot 17$ & $0.99,1.39$ & $1 \cdot 14$ & $0.98,1.33$ \\
\hline & Quartile 3 & $1 \cdot 37$ & $1.16,1.61$ & 1.35 & $1.14,1.60$ & $1 \cdot 34$ & $1.13,1.59$ & 1.36 & $1.18,1.57$ \\
\hline & Quartile 4 & $1 \cdot 31$ & $1 \cdot 11,1.54$ & 1.29 & $1.08,1.54$ & $1 \cdot 29$ & $1.08,1.53$ & $1 \cdot 20$ & $1.03,1.40$ \\
\hline \multirow{4}{*}{$\begin{array}{l}\text { Incident obesity among the } \\
\text { overweight } \\
\left(\mathrm{BMI} \geq 30 \mathrm{~kg} / \mathrm{m}^{2}\right) \dagger \\
(n 4771)\end{array}$} & $\begin{array}{l}\text { For each } 15 \% \\
\text { point increase }\end{array}$ & $1 \cdot 20$ & $1 \cdot 09,1 \cdot 33$ & $1 \cdot 12$ & $1 \cdot 01,1 \cdot 25$ & $1 \cdot 13$ & $1 \cdot 01,1 \cdot 26$ & 1.06 & $0.96,1.17$ \\
\hline & Quartile 2 & $1 \cdot 17$ & $0.97,1.42$ & $1 \cdot 11$ & $0.92,1.34$ & $1 \cdot 12$ & $0.92,1.35$ & $1 \cdot 12$ & $0.95,1.32$ \\
\hline & Quartile 3 & $1 \cdot 10$ & $0.90,1.34$ & 1.02 & $0.84,1.24$ & 1.03 & $0.85,1.26$ & $1 \cdot 01$ & $0.85,1.21$ \\
\hline & Quartile 4 & $1 \cdot 25$ & $1.04,1.51$ & $1 \cdot 10$ & $0.90,1.34$ & $1 \cdot 11$ & $0.91,1.36$ & 1.02 & $0.85,1.21$ \\
\hline
\end{tabular}

$\mathrm{RR}$, relative risk

Model 1: crude.

Model 2: plus age, sex, colour/race, centre, income and school achievement.

Model 3: plus smoking and physical activity.

Model 4: for incident overweight/obesity and weight gain, plus baseline BMI; for waist gain, plus waist circumference at baseline.

Quartile 1 is always the reference quartile.

${ }^{*}$ Among those with $\mathrm{BMl}<25 \mathrm{~kg} / \mathrm{m}^{2}$ at baseline.

†Among those with BMI between 25 and $30 \mathrm{~kg} / \mathrm{m}^{2}$ at baseline.

Investigating a cohort of university alumni in Spain, they found similar associations (hazard ratio $=1 \cdot 26,95 \% \mathrm{CI}$ $1 \cdot 10,1.45$ for consumption of $6 \cdot 1$ (SD 0.9) $v .1 .5$ (SD 0.9) portions of ultra-processed foods daily). Our results significantly extend their findings by including adults residing in a middle-income country with a wider range of educational achievement, ethnicity and age, which is important considering the recent trends for increasing consumption of ultra-processed foods in these countries ${ }^{(4)}$. By investigating a wider scope of obesity/central obesity outcomes, we were able to demonstrate a similar association with gain in waist circumference. Moreover, after excluding sweetened beverages from the NOVA classification of ultra-processed foods, in a secondary analysis, we found similar associations, demonstrating that the risk associated with ultraprocessed foods does not result solely from sweetened beverages.

The use of the NOVA classification has recently been criticized $^{(29)}$ as lacking support from human studies demonstrating risk; being too dependent on added sugars; lacking underlying biological mechanisms to explain possible harm; and being too broad to be useful.

In fact, evidence to support its risk is growing, now extending also to incident cancer ${ }^{(30)}$ and overall mortality ${ }^{(31)}$. With regard to obesity, our findings confirm the role of ultra-processed foods in incident overweight and obesity found by Mendonça et $\mathrm{al}$. and by one small study of weight gain in pregnancy ${ }^{(32)}$, as well cross-sectional evidence originated in different countries and settings, which almost uniformly suggests risk ${ }^{(10,27,33-35)}$. Moreover, our findings that associations remained after exclusion of sugar-sweetened beverages suggest that excess sugar ${ }^{(36)}$ is not the only culprit.

Possible mechanisms to explain the associations between ultra-processed foods and obesity can be outlined, the first one being the increased energy intake associated with the consumption of ultra-processed foods ${ }^{(37)}$. Ultra-processed food products, compared with the other groups of foods, show greater energy density, as well as greater total and saturated fat, trans fats and sugar, and less fibre, protein and potassium, which illustrates their generally poor nutritional value ${ }^{(38)}$. Being designed to favour consumption and satiate less ${ }^{(39)}$ they can be consumed more frequently and in larger portions, contributing to increased energy intake. Being relatively low in protein, they may also increase intake because of the proposed dominant drive for protein intake ${ }^{(40)}$. However, our findings and those of Mendonça et al. showing increased risk even after adjusting for daily total energy intake suggest that additional mechanisms are at play. It is also possible that the intake of ultra-processed foods dislocates more healthy foods from 
the daily diet. However, our associations changed only minimally when we adjusted for fruits and vegetables, indicating that associations do not result solely from eating less of these foods.

Another line of potential mechanism involves the food additives in ultra-processed foods. Emulsifiers, common in ultra-processed products, led to disruption in the intestinal mucus barrier in mice, producing chronic inflammation and the metabolic syndrome ${ }^{(41)}$, a phenotype linked to weight gain. Eating a Western ( $v$. more traditional) diet, which increases consumption of food additives, produces alteration in the distinct combination of bacteria in the intestine, the result of which may be a more dysfunctional metabolic status $^{(42,43)}$. Consumption of soda, which includes multiple additives, has been associated with a lower level of Akkermansia muciniphila, believed to be protective against obesity and type 2 diabetes. Snack and junk food products, often characterized by the long list of additives among their ingredients, have been associated with higher counts of Escherichia coli and a lesser presence of lactobacilli and butyrate-producing Firmicutes species, these alterations believed to lead to detrimental inflammatory effects within the gut milieu ${ }^{(44)}$.

Finally, although the concept of ultra-processed food may be broad, it can be useful for public health, as shown by its application as the basis of current national nutritional guidelines in Brazil and Uruguay ${ }^{(45,46)}$

The consumption of ultra-processed foods has increased remarkably in the last decades worldwide, replacing the consumption of minimally processed and fresh foods. In Canada, the dietary share of ultra-processed products in the average household food basket in the $1930 \mathrm{~s}$ was $24.4 \%$ and in the early 2000 s, $54 \%^{(6)}$. Other highincome countries also show major contributions of ultraprocessed foods to energy intake, being larger when compared with that of middle-income countries ${ }^{(6,47)}$. This larger share of consumption may result from marketing strategies similar to those used for selling tobacco products $^{(48)}$. In middle-income countries consumption of ultra-processed foods has increased more recently and more rapidly ${ }^{(4)}$. In Brazil, ultra-processed foods accounted for $19.2 \%$ of total energy intake in $1987-1988^{(3)}$, reaching $25.4 \%$ in 2008-2009 ${ }^{(5)}$, a percentage which was also found in the baseline of the ELSA-Brasil population ${ }^{(49)}$. Of note also, we found greater consumption among the more educated/higher-income individuals, consistent with previous findings in $\mathrm{Brazil}^{(5)}$. The rising trend in ultraprocessed food consumption in low- and middle-income countries is likely to continue and may change from its current sociodemographic distribution. In Brazil, $61 \%$ of food advertising on open television was for ultra-processed foods $v$. only $7 \%$ for in natura or minimally processed foods ${ }^{(50)}$. These factors, all together, influence food choice and eating behaviours, and thus alter eating patterns in the population, frequently without individual awareness or control ${ }^{(51)}$.
Our study has some limitations. First, FFQ, although traditionally used to assess nutritional intake in epidemiological studies, are imprecise and may under- or overestimate total energy intake. However, our measure of consumption of ultra-processed foods as a percentage of total energy intake minimizes problems related to under- or overestimation. Our version was not specifically designed for use with the NOVA classification. Despite this, the frequency of ultraprocessed food consumption we report is consistent with that of a nationwide representative survey ${ }^{(38)}$. We cannot rule out reporting bias, although the hypothesis that ultraprocessed foods cause weight gain was not recognized in Brazil during baseline interviews. Moreover, non-differential misinformation, if present, is more likely to bias towards the null. Second, our follow-up of approximately 4 years resulted in our outcome being assessed over a relatively short period of time. Third, although adjustments were made for possible confounders in statistical analyses, it is not possible to rule out residual confounding.

Our study also has strengths. First, this is a large contemporary cohort study with small losses to follow-up ( $<6 \%$ ). Second, we performed highly standardized measurements, including waist circumference, with strict quality control. Third, our spline analyses permit a detailed evaluation of change in risk across the spectrum of ultra-processed food consumption. Fourth, our various sensitivity analyses confer robustness to the interpretation of our findings.

Our findings are consistent with previous studies ${ }^{(10,11)}$, supporting the contention that high consumption of ultra-processed foods may contribute to the current obesity epidemic in Brazil. Although issues of external validity need to be taken into consideration, our finding may apply also to the obesity epidemic in other settings as many have a similar pattern of increasing consumption of ultraprocessed foods over the period of rising obesity ${ }^{(10)}$. Consumption of ultra-processed foods has increased globally as marketing strategies have progressively targeted an increasing fraction of the world's population, initially in high-income countries and more recently in low- and middle-income countries ${ }^{(4)}$.

Public policies to reduce ultra-processed foods are now being implemented in different countries. Policies restricting or banning the sale of sugar-sweetened beverages and confectioneries in schools and other institutional or commercial settings have been implemented in several countries ${ }^{(52)}$. Brazil and Uruguay have developed dietary guidelines explicitly referring to the category of ultra-processed foods and advising the population not to replace minimally processed foods and their culinary preparations with ultra-processed food and drink products ${ }^{(45,46)}$.

\section{Conclusion}

In conclusion, we provide prospective evidence that consumption of ultra-processed foods and beverages is related 
to gains in overall and central adiposity, and to incident overweight/obesity among those not so at baseline, in a broad, free-living population. Public policies aimed at reducing the consumption of ultra-processed foods may help revert the to-date inexorable rise in obesity in Brazil and elsewhere.

\section{Acknowledgements}

Acknowledgements: The authors thank the staff and participants of ELSA-Brasil for their important contributions. Financial support: The study was supported by the Brazilian Ministry of Health (Department of Science and Technology) and Ministry of Science, Technology and Innovation (Financiadora de Estudos e Projetos (FINEP); grant numbers 0106 0010.00, 0106 0212.00, 0106 0300.00, 0106 0278.00, 01060115.00 and 01060071.00 ) and the National Council for Scientific and Technological Development (CNPq). S.L.C. received a fellowship from Fundação de Amparo à Pesquisa do Estado de Rio Grande do Sul (FAPERGS), through its support for the Instituto de Avaliação de Tecnologia em Saúde. Researchers were independent from funders. Funders had no role in the study design; the collection, analysis and interpretation of data; the writing of the report; or the decision to submit the article for publication. The corresponding author affirms that she had full access to all the data in the study and had final responsibility for the decision to submit for publication. Conflict of interest: None. Authorship: S.L.C. performed the statistical analysis, wrote the manuscript and had primary responsibility for the final content; V.C.L. reviewed the data analysis, reviewed the manuscript and had primary responsibility for the final content; B.B.D. and M.I.S. designed the research, reviewed the manuscript and had primary responsibility for the final content; D.C. and S.M.B. designed the research and reviewed the manuscript; L.G., M.J.F., S.M.A.M., M.C.B.M. and R.B.L. reviewed the manuscript. Ethics of human subject participation: This study was conducted according to the guidelines laid down in the Declaration of Helsinki and all procedures involving research study participants were approved by the ethics committee of all the institutions involved (Fundação Oswaldo Cruz, Universidade Federal da Bahia, Universidade Federal do Espírito Santo, Universidade Federal de Minas Gerais, Universidade Federal do Rio Grande do Sul and Universidade de São Paulo). Written informed consent was obtained from all participants.

\section{References}

1. GBD 2015 Obesity Collaborators, Afshin A, Forouzanfar MH et al. (2017) Health effects of overweight and obesity in 195 countries over 25 years. N Engl J Med 377, 13-27.
2. World Health Organization (2014) Global Status Report on Noncommunicable Diseases 2014. WHO/NMH/NVI/15.1. Geneva: WHO.

3. Monteiro CA, Levy RB, Claro RM et al. (2011) Increasing consumption of ultra-processed foods and likely impact on human health: evidence from Brazil. Public Health Nutr 14, 5-13.

4. Monteiro CA, Moubarac JC, Cannon G et al. (2013) Ultraprocessed products are becoming dominant in the global food system. Obes Rev 14, 21-28.

5. Martins APB, Levy RB, Claro RM et al. (2013) Increased contribution of ultra-processed food products in the Brazilian diet (1987-2009). Rev Saude Publica 47, 656-665.

6. Moubarac JC, Batal M, Martins APB et al. (2014) Processed and ultra-processed food products: consumption trends in Canada from 1938 to 2011. Can J Diet Pract Res 75, 15-21.

7. Juul F \& Hemmingsson E (2015) Trends in consumption of ultra-processed foods and obesity in Sweden between 1960 and 2010. Public Health Nutr 18, 3096-3107.

8. Baker P \& Friel S (2016) Food systems transformations, ultraprocessed food markets and the nutrition transition in Asia. Global Health 12, 80.

9. Venn D, Banwell C \& Dixon J (2017) Australia's evolving food practices: a risky mix of continuity and change. Public Health Nutr 20, 2549-2558.

10. Monteiro CA, Moubarac JC, Levy RB et al. (2018) Household availability of ultra-processed foods and obesity in nineteen European countries. Public Health Nutr 21, 18-26.

11. Mendonça RD, Pimenta AM, Gea A et al. (2016) Ultraprocessed food consumption and risk of overweight and obesity: the University of Navarra Follow-Up (SUN) cohort study. Am J Clin Nutr 104, 1433-1440.

12. Schmidt MI, Duncan BB, Mill JG et al. (2015) Cohort profile: Longitudinal Study of Adult Health (ELSA-Brasil). Int $J$ Epidemiol 44, 68-75.

13. Aquino EML, Barreto SM, Bensenor IM et al. (2012) Brazilian Longitudinal Study of Adult Health (ELSA-Brasil): objectives and design. Am J Epidemiol 175, 315-324.

14. Aquino EML, Araujo MJ, da Conceição C et al. (2013) Participants recruitment in ELSA-Brasil (Brazilian Longitudinal Study for Adult Health). Rev Saude Publica 47, Suppl. 2, 10-18.

15. Bensenor IM, Griep RH, Pinto KA et al. (2013) Routines of organization of clinical tests and interviews in the ELSABrasil investigation center. Rev Saude Publica 47, Suppl. $2,37-47$.

16. Lohman TG \& Roche AF (1992) Anthropometric Standardization Reference Manual. Champaign, IL: Human Kinetics Books.

17. Schmidt MI, Griep RH, Passos VM et al. (2013) Strategies and development of quality assurance and control in the ELSABrasil. Rev Saude Publica 47, Suppl. 2, 105-112.

18. Molina MDCB, Benseñor IM, Cardoso L de O et al. (2013) Reproducibility and relative validity of the food frequency questionnaire used in the ELSA-Brasil. Cad Saude Publica 29, 379-389.

19. Monteiro CA, Cannon G \& Levy RB (2016) NOVA. The star shines bright. World Nutr 7, 28-38.

20. Desquilbet L \& Mariotti F (2010) Dose-response analyses using restricted cubic spline functions in public health research. Stat Med 29, 1037-1057.

21. Newson RB (2013) Attributable and unattributable risks and fractions and other scenario comparisons. Stata J 13, 672-698.

22. Mansournia MA \& Altman DG (2018) Population attributable fraction. BMJ 360, $\mathrm{k} 757$

23. Malik VS, Schulze MB \& Hu FB (2006) Intake of sugarsweetened beverages and weight gain: a systematic review. Am J Clin Nutr 84, 274-288.

24. Rosenheck R (2008) Fast food consumption and increased caloric intake: a systematic review of a trajectory towards weight gain and obesity risk. Obes Rev $\mathbf{9}, 535-547$. 
25. Mozaffarian D, Hao T, Rimm EB et al. (2011) Changes in diet and lifestyle and long-term weight gain in women and men. N Engl J Med 364, 2392-2404.

26. Canella DS, Levy RB, Martins APB et al. (2014) Ultraprocessed food products and obesity in Brazilian households (2008-2009). PLoS One 9, e92752.

27. Louzada ML da C, Baraldi LG, Steele EM et al. (2015) Consumption of ultra-processed foods and obesity in Brazilian adolescents and adults. Prev Med 81, 9-15.

28. Pan American Health Organization (2015) Ultra-Processed Food and Drink Products in Latin America: Trends, Impact on Obesity, Policy Implications. Washington, DC: PAHO.

29. Gibney MJ, Forde CG, Mullally D et al. (2017) Ultra-processed foods in human health: a critical appraisal. Am JClin Nutr 106, 717-724.

30. Fiolet T, Srour B, Sellem L et al. (2018) Consumption of ultraprocessed foods and cancer risk: results from NutriNet-Santé prospective cohort. BMJ 360, k322.

31. Schnabel L, Kesse-Guyot E, Allès B et al. (2019) Association between ultraprocessed food consumption and risk of mortality among middle-aged adults in France. JAMA Intern Med 179, 490-498.

32. Rohatgi KW, Tinius RA, Cade WT et al. (2017) Relationships between consumption of ultra-processed foods, gestational weight gain and neonatal outcomes in a sample of US pregnant women. PeerJ 5, e4091.

33. Monteiro CA, Cannon G, Moubarac J-C et al. (2018) Ultraprocessing. An odd 'appraisal'. Public Health Nutr 21, 497-501.

34. Costa CS, Del-Ponte B, Assunção MCF et al. (2018) Consumption of ultra-processed foods and body fat during childhood and adolescence: a systematic review. Public Health Nutr 21, 148-159.

35. Juul F, Martinez-Steele E, Parekh N et al. (2018) Ultraprocessed food consumption and excess weight among US adults. Br J Nutr 120, 90-100.

36. Te Morenga L, Mallard S \& Mann J (2012) Dietary sugars and body weight: systematic review and meta-analyses of randomised controlled trials and cohort studies. BMJ 346, e7492.

37. Prentice AM \& Jebb SA (2003) Fast foods, energy density and obesity: a possible mechanistic link. Obes Rev 4, 187-194.

38. Costa Louzada ML, Martins APB, Canella DS et al. (2015) Ultra-processed foods and the nutritional dietary profile in Brazil. Rev Saude Publica 49, 38.

39. Fardet A (2016) Minimally processed foods are more satiating and less hyperglycemic than ultra-processed foods: a preliminary study with 98 ready-to-eat foods. Food Funct 7, 2338-2346.
40. Simpson SJ \& Raubenheimer D (2005) Obesity: the protein leverage hypothesis. Obes Rev 6, 133-142.

41. Chassaing B, Koren O, Goodrich JK et al. (2015) Dietary emulsifiers impact the mouse gut microbiota promoting colitis and metabolic syndrome. Nature 519, 92-96.

42. Flint HJ, Scott KP, Louis P et al. (2012) The role of the gut microbiota in nutrition and health. Nat Rev Gastroenterol Hepatol 9, 577-589.

43. Graf D, Di Cagno R, Fåk F et al. (2015) Contribution of diet to the composition of the human gut microbiota. Microb Ecol Health Dis 26, 26164.

44. Mitsou EK, Kakali A, Antonopoulou S et al. (2017) Adherence to the Mediterranean diet is associated with the gut microbiota pattern and gastrointestinal characteristics in an adult population. Br J Nutr 117, 1645-1655.

45. Monteiro CA, Cannon G, Moubarac J-C et al. (2015) Dietary guidelines to nourish humanity and the planet in the twentyfirst century. A blueprint from Brazil. Public Health Nutr 18, $2311-2322$

46. Food and Agriculture Organization of the United Nations (2017) Food-based dietary guidelines - Uruguay. http:// www.fao.org/nutrition/education/food-based-dietary-guid elines/regions/countries/uruguay/en/ (accessed March 2017).

47. Solberg SL, Terragni L \& Granheim SI (2016) Ultra-processed food purchases in Norway: a quantitative study on a representative sample of food retailers. Public Health Nutr 19, 1990-2001.

48. Moodie R, Stuckler D, Monteiro C et al. (2013) Profits and pandemics: prevention of harmful effects of tobacco, alcohol, and ultra-processed food and drink industries. Lancet 381, 670-679.

49. Simões BS, Barreto SM, Molina MDCB et al. (2018) Consumption of ultra-processed foods and socioeconomic position: a cross-sectional analysis of the Brazilian Longitudinal Study of Adult Health. Cad Saude Publica 34, e00019717.

50. Maia EG, Costa BVL, Coelho FS et al. (2017) Analysis of TV food advertising in the context of recommendations by the Food Guide for the Brazilian Population. Cad Saude Publica 33, e00209115.

51. Cohen DA (2008) Obesity and the built environment: changes in environmental cues cause energy imbalances. Int J Obes (Lond) 32, Suppl. 7, S137-S142.

52. Hawkes C, Jewell J \& Allen K (2013) A food policy package for healthy diets and the prevention of obesity and dietrelated non-communicable diseases: the NOURISHING framework. Obes Rev 14, 159-168. 